This article was downloaded by: [Dalhousie University]

On: 10 September 2012, At: 04:48

Publisher: Taylor \& Francis

Informa Ltd Registered in England and Wales Registered Number: 1072954 Registered office: Mortimer House, 37-41 Mortimer Street, London W1T 3J H, UK

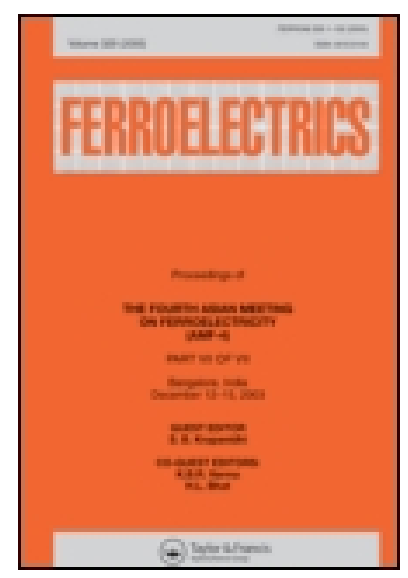

\title{
Ferroelectrics
}

Publication details, including instructions for authors and subscription information:

http:// www. tandfonline.com/loi/ gfer20

\section{XRD Study of New FLC's: Correlation Between the Chemical Structure of Molecules, the Sign of the Optical Rotation and the Tilt Angle}

\author{
V. Lapanik ${ }^{b}$, V. Bezborodov ${ }^{\text {b }}$, W. Haase ${ }^{a} \&$ A. Lapanik ${ }^{a}$ \\ a Institute of Physical Chemistry, Darmstadt University of \\ Technology, Darmstadt, 64287, Germany \\ ${ }^{b}$ Institute of Applied Physics Problems, Belarusian State University, \\ Minsk, 220064, Belarus
}

Version of record first published: 10 Mar 2011

To cite this article: V. Lapanik, V. Bezborodov, W. Haase \& A. Lapanik (2006): XRD Study of New FLC's: Correlation Between the Chemical Structure of Molecules, the Sign of the Optical Rotation and the Tilt Angle, Ferroelectrics, 343:1, 127-132

To link to this article: http:// dx.doi.org/ 10.1080/00150190600962226

\section{PLEASE SCROLL DOWN FOR ARTICLE}

Full terms and conditions of use: http://www.tandfonline.com/page/terms-and-conditions

This article may be used for research, teaching, and private study purposes. Any substantial or systematic reproduction, redistribution, reselling, loan, sub-licensing, systematic supply, or distribution in any form to anyone is expressly forbidden.

The publisher does not give any warranty express or implied or make any representation that the contents will be complete or accurate or up to date. The accuracy of any instructions, formulae, and drug doses should be independently verified with primary sources. The publisher shall not be liable for any loss, actions, claims, proceedings, demand, or costs or damages whatsoever or howsoever caused arising directly or indirectly in connection with or arising out of the use of this material. 


\title{
XRD Study of New FLC's: Correlation Between the Chemical Structure of Molecules, the Sign of the Optical Rotation and the Tilt Angle
}

\author{
V. LAPANIK, ${ }^{2}$ V. BEZBORODOV,${ }^{2}$ W. HAASE,${ }^{1}$ \\ AND A. LAPANIK ${ }^{1, *}$ \\ ${ }^{1}$ Institute of Physical Chemistry, Darmstadt University of Technology, 64287, \\ Darmstadt, Germany \\ ${ }^{2}$ Institute of Applied Physics Problems, Belarusian State University, \\ Minsk 220064, Belarus
}

\begin{abstract}
New 4-ring FLC's with different positions of lateral substituents and bridge fragments in the central core were synthesized. These compounds have a wide temperature range of the smectic $C^{*}$ phase and similar length of the molecules. Different ways of the preparation of the FLC mixtures with a high tilt angle and the results of electrooptical and XRD measurements of the FLC mixtures based upon the chiral compounds are presented.
\end{abstract}

Keywords Ferroelectric; liquid crystalline materials; tilt angle; XRD

\section{Introduction}

The development of mixtures with a high optical tilt angle and a broad range of the SmC phase play the key role in the production and the practical application of the ferroelectric liquid crystalline (FLC) displays. One of the main parameters of FLC cells for displays is the contrast ratio which is strongly depended on the tilt angle of the FLC mixtures or single compounds and is responsible for the quality of the image of a display. It is well known, that the optical tilt angle can be directly measured by the electro-optical methods. Unfortunately, the accuracy is unsatisfactory and sometimes it is impossible to carry out the measurements fast and successfully [1]. In contrast to this, the X-ray diffraction (XRD) on smectic layers allows to measure the tilt angle of the molecules with high accuracy and does not need much time and good practical skills of the preparation of testing cells. But, it should be noted, that the XRD data correspond to the tilt angle of the whole molecules in the smectic layers, whereas the electro-optical measurements - to the angle of more tilted central core of the molecules, which is always larger than the previous one [2].

Nevertheless, in spite of these differences, it is clear, that the optical tilt angle within certain chemical classes can be easy estimated from the X-ray data, using the ratio between the two tilt angles.

Received September 12, 2005.

${ }^{*}$ Corresponding author. E-mail: artem.lapanik@web.de 
Chiral mesomorphic 4,4'-disubstituted biphenyls as well as similar terphenyl derivatives are promising candidates for the use in liquid crystal mixtures intended for FLC displays. These compounds are characterized by low melting points, a wide temperature range of $\mathrm{SmC}^{*}$ phase and high values of the tilt angle. In order to continue our investigations of the mesomorphic and physical properties of ferroelectric derivatives of biphenyl and terphenyl and to ascertain the regularities in the change in their tilt angle depending on the chemical structure of the molecules, as well as the variation of the parameters of the FLC mixtures containing these compounds, we have prepared the new four-ring FLC compounds (SC-5, SC-48, SC-90, SC-91, SC-92, SC-94, SC-95, SC-97, SC-98) with different types and the positions of lateral substituents and bridge fragments in the central core [3]. These compounds have a wide temperature range of the smectic $\mathrm{C}^{*}$ phase and similar length of the molecules.
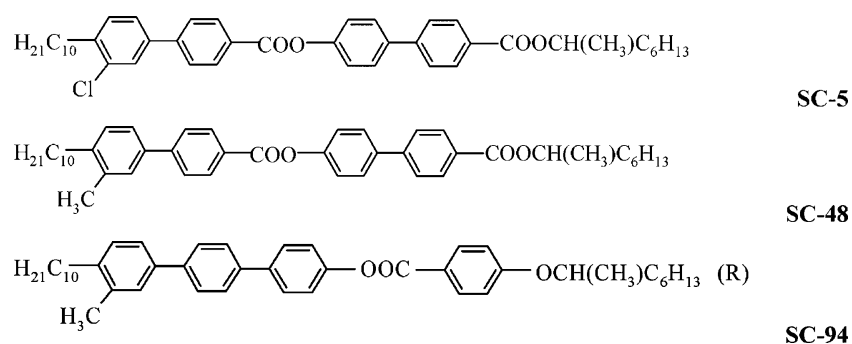

$\mathrm{SC}-48$

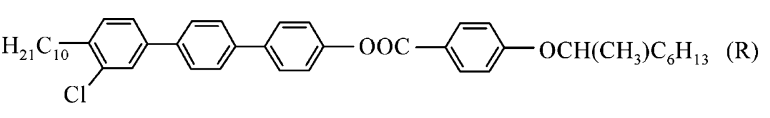

SC-94

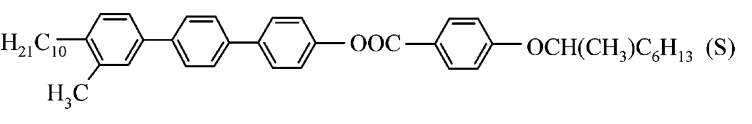

SC-98

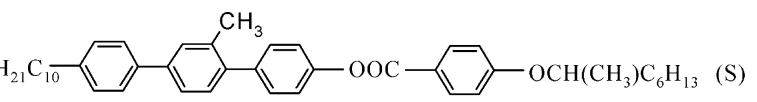

SC-90

SC-91

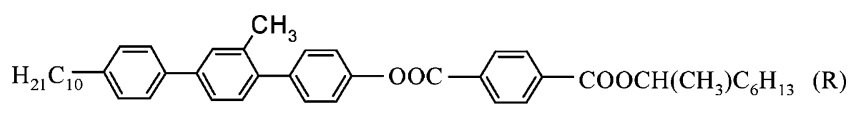

SC-95

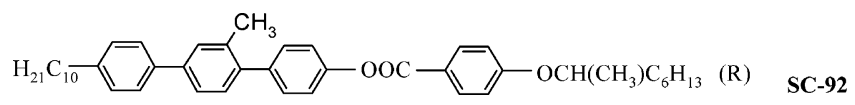

SC-97

In this paper we describe the influence of the molecular structure of synthesized compounds on the tilt angle and the layer thickness of $\mathrm{Sm} \mathrm{C}^{*}$ phase.

\section{Results and Discussion}

We investigated the main physical properties (tilt angle, temperature range of the $\mathrm{SmC}^{*}$ phase and spontaneous polarization) and performed X-ray measurements (thickness of the 
Table 1

Electrooptical and X-ray properties of single compounds (SC) and of mixtures

\begin{tabular}{|c|c|c|c|c|c|c|}
\hline Mixtures & $\begin{array}{c}\mathrm{SmC}^{*} \\
\text { temperature } \\
\text { range }\left[{ }^{\circ} \mathrm{C}\right]\end{array}$ & $\begin{array}{c}\text { Spontaneous } \\
\text { polarization } \\
{\left[\mathrm{nC} / \mathrm{cm}^{2}\right]}\end{array}$ & $\begin{array}{c}\text { Tilt angle } \\
{\left[^{\circ}\right]} \\
\text { electro-optical }\end{array}$ & $\begin{array}{c}\mathrm{d}[\AA] \text { in } \\
\mathrm{SmC}^{*}\end{array}$ & $\begin{array}{c}\mathrm{d}[\AA] \text { in } \\
\mathrm{SmA}\end{array}$ & $\begin{array}{r}\text { Tilt angle } \\
\text { extracted } \\
\text { from X-ray } \\
\text { data }\left[{ }^{\circ}{ }^{\circ}\right.\end{array}$ \\
\hline LBHS-37 & $<20-120.9$ & - & 27.7 & 28.6 & - & - \\
\hline LBHS- 38 & $<20-119.5$ & - & 23.2 & 28.5 & - & - \\
\hline LBHS- 39 & $<20-117.1$ & - & 22.8 & 28.7 & - & - \\
\hline LBHS-40 & $<20-118.2$ & - & 27.1 & 28.6 & - & - \\
\hline SC-5 & $37-139$ & 160 & 44.0 & 31.2 & 37.5 & 33.6 \\
\hline SC-48 & 44-107 & 140 & 36.8 & 33.6 & 37.5 & 26.4 \\
\hline SC-90 & $<20-113.5$ & 175 & 35.7 & 28.4 & - & 28.1 \\
\hline SC-91 & $(70.2)$ & - & 37.1 & 26.5 & - & 29.6 \\
\hline SC-92 & $(70.3)$ & - & 37.7 & 26.6 & - & 29.5 \\
\hline SC-94 & $<20-123.6$ & 170 & 35.8 & 28.4 & - & 28.1 \\
\hline SC-95 & $52-93$ & & 38.5 & 29.9 & - & 30.5 \\
\hline SC-97 & $<20-110.3$ & 172 & 37.0 & 25.6 & - & 29.0 \\
\hline SC-98 & $<20-132.4$ & 175 & 38.8 & 27.5 & - & 31.0 \\
\hline
\end{tabular}

smectic layers) of all synthesized compounds and some FLC mixtures based upon them. The obtained results are presented in Tables 1 and 2.

As can be seen from the electro-optical measurements (Table 1) the tilt angle for SC-5 is larger as for SC-48 and for SC-98 is larger than for SC-94. The difference between the single compounds in these two pairs is only in lateral substituents in the same positions of the central core: $(\mathrm{Cl})$ for SC-5 and SC-98 and $\left(\mathrm{CH}_{3}\right)$ for SC-48 and SC-94. The temperature dependences of the tilt angles of SC-5 and SC-58 are presented in figure 1 and show that the substitution of the $\mathrm{CH}_{3}$ group by a $\mathrm{Cl}$ atom leads to the increasing of the tilt angle by 10 degrees. It was also found that the lateral $\mathrm{CH}_{3}$ derivatives, compared to the $\mathrm{Cl}$ derivatives, have higher transition temperatures from the crystalline to smectic $\mathrm{C}^{*}$ phase [4].

The XRD data confirmed the results of the electro-optical measurements of these FLC compounds. As can be seen from Fig. 2, the thickness of the SmC* layers of SC-5 is smaller than of SC-48. Since both compounds have the same molecular length we can conclude that the tilt angle in case of SC-5 is enlarged, compared to SC-48 (see Table 1). It is clear that the substitution of a $\mathrm{CH}_{3}$ group by a $\mathrm{Cl}$ atom leads to the increase of the tilt angle.

Additionally to these measurements we investigated the influence of the sign of the optical rotation on the thickness of smectic layers (see Table 1). From the results of the investigations of four single compounds (SC-90, SC-91, SC-92 and SC-94) and four mixtures

Table 2

FLC mixtures based on left and right handed chiral compounds

\begin{tabular}{lcccc}
\hline Compounds & LBHS-37 wt\% & LBHS-38 wt\% & LBHS-39wt\% & LBHS-40 wt\% \\
\hline SC-90 (S+) & 10 & 30 & 70 & 90 \\
SC-94 (R-) & 90 & 70 & 30 & 10 \\
\hline
\end{tabular}




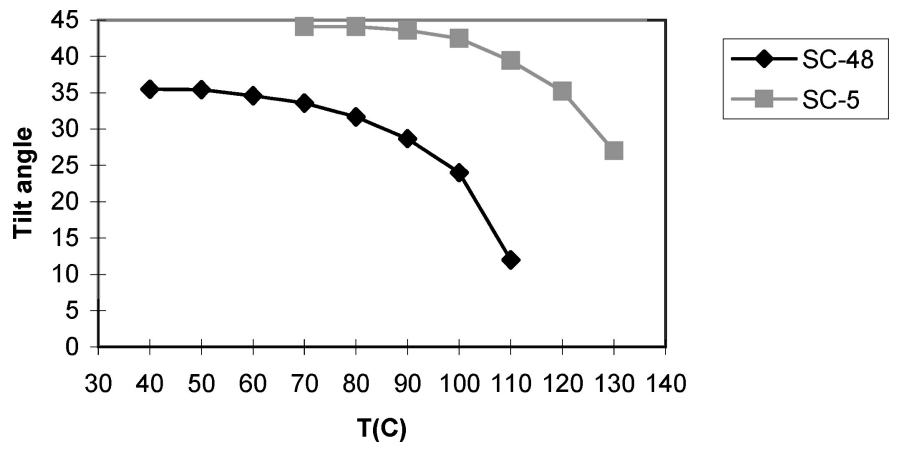

Figure 1. Temperature dependence of the tilt angle for SC-5 and SC-48.

(LBHS-37 and LBHS-38, LBHS-39 and LBHS-40 (see Table 2)) we have found that the thickness of the SmC* layers for SC-90 and SC-94 (left and right handed) is in full agreement with the thickness of SC-91 and SC-92 (right and left handed) (see Table 1).

As can be seen from XRD data there are no changes in the thickness of smectic layers when we mix right- and left-handed components in different proportions (see Fig. 3), but the electro-optical measurements indicated that there is a difference in the tilt angles of these mixtures and of single compounds. In spite of that the tilt angle for each of the two pairs of single components (SC-90 and SC-94, SC-91 and SC-92) is the same, but for the FLC mixtures (LBHS-38 and LBHS-39, LBHS-37 and LBHS-40) the tilt angle is lower (see Table 1).

In continuation of our investigation we have used other pair of FLC compounds (SC-91 and SC-90). Both single compounds are left-handed with the same molecular length. The difference between them is only the position of the $\mathrm{CH}_{3}$ substituent in the central core.

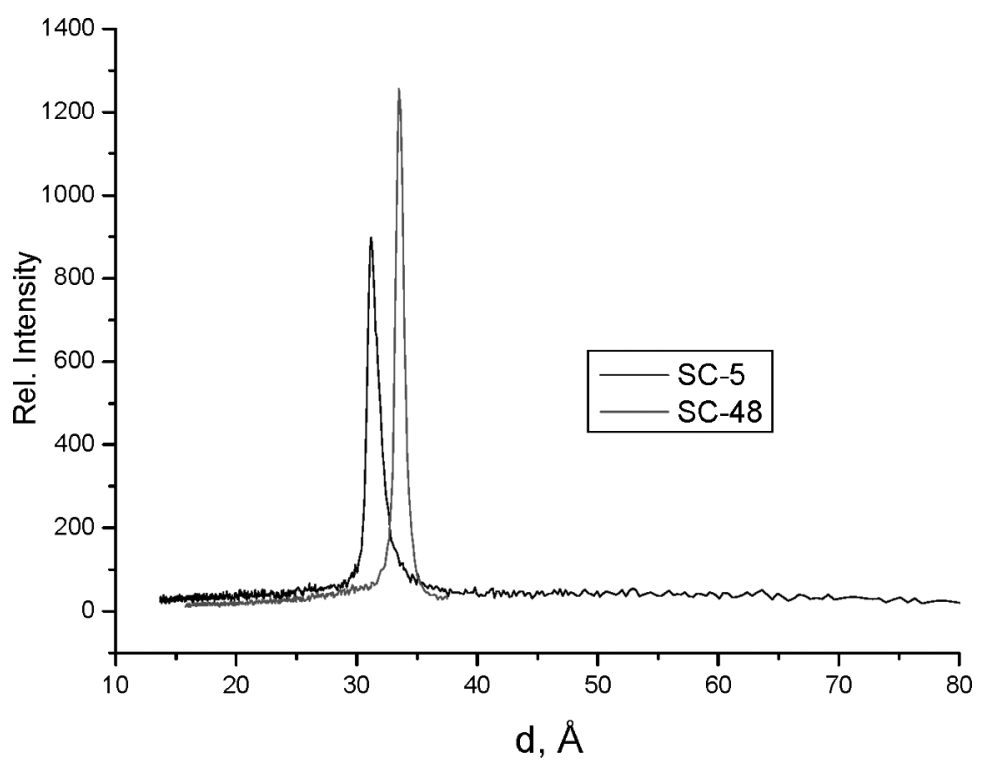

Figure 2. XRD pattern for SC-5 and SC- 48 at $75^{\circ} \mathrm{C}$. (See Color Plate V). 


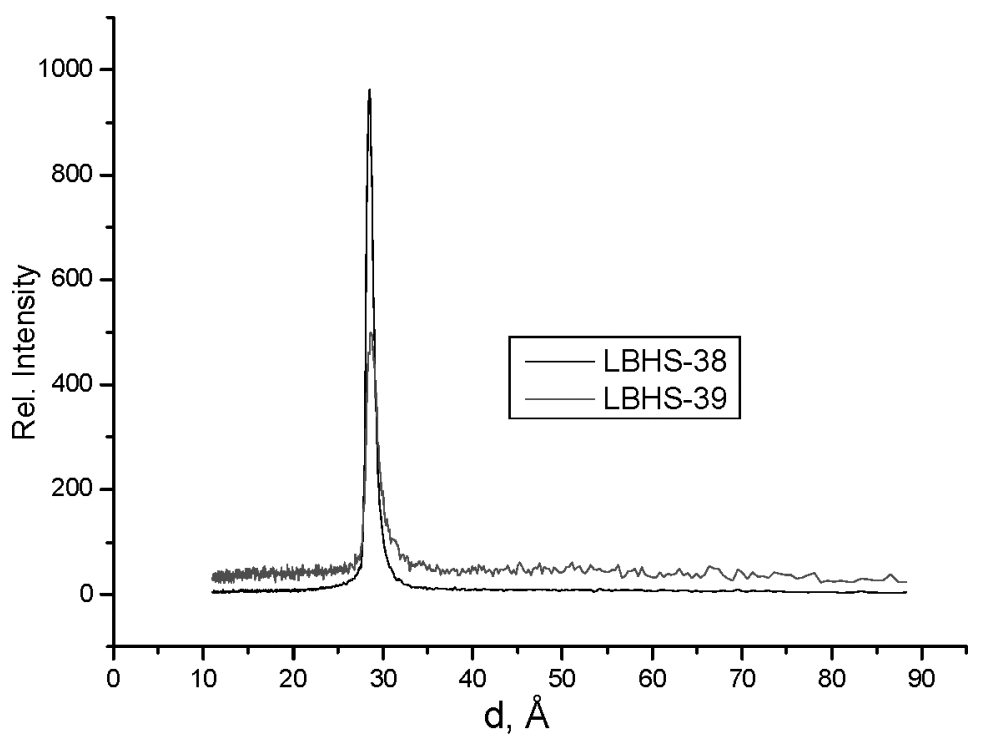

Figure 3. XRD pattern for LBHS-38 and LBHS-39 at $57^{\circ}$ C. (See Color Plate VI).

$\mathrm{X}$-ray measurements of these compounds have shown that the thickness of the $\mathrm{SmC}^{*}$ layer for SC-91 is lower than for SC-90 (see Table 1 and Fig. 4). It may be explained by a different packing of molecules inside the layer, leading to the different tilt of them. It should be noted that these results are in agreement with results from electro-optical measurements (see Table 1).

For the investigation of the influence of the length of alkyl chain on the tilt angle we have used the (SC-94 and SC-97) single compounds. The results of the electro-optical measurements of these compounds demonstrated that the tilt angle of a compound with

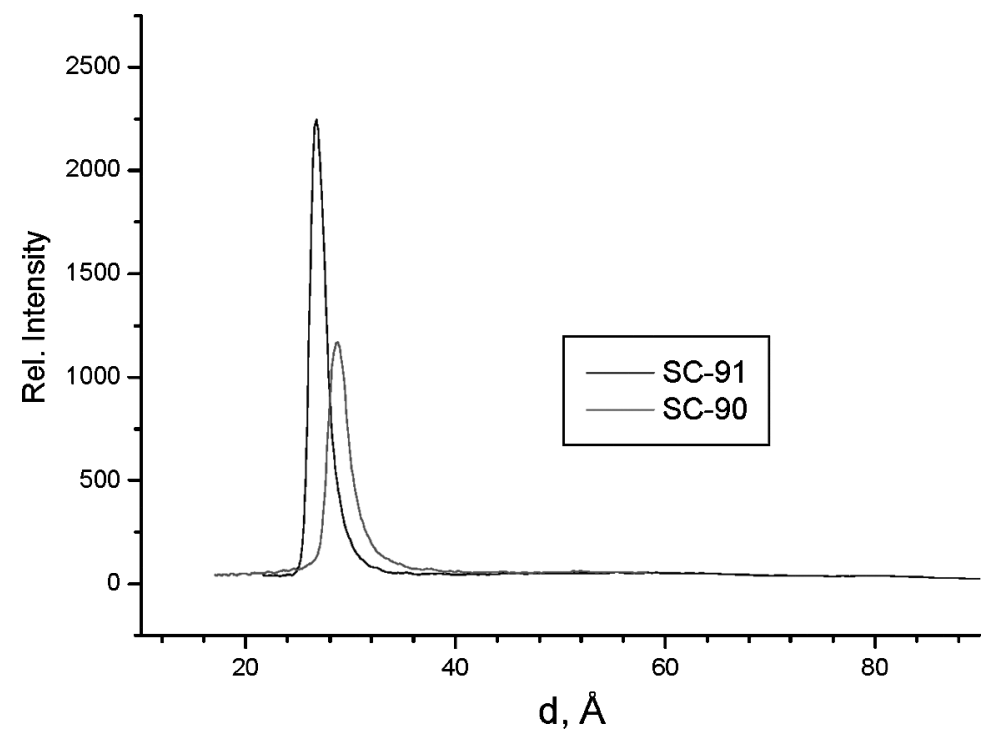

Figure 4. XRD pattern for SC 90 and SC 91 at $57^{\circ} \mathrm{C}$. (See Color Plate VII). 
shorter alkyl chain (SC-97) is higher in comparison to SC-94 (see Table 1). The same results we have got for other single compounds. The decrease of the length of the alkyl chain results in a higher tilt angle.

Finally, on the example of the esters (SC-92 and SC-95) we studied the influence of the positions and the amount of $\mathrm{COO}$ bridge fragments on the tilt angle and the thickness of the smectic layers of the FLC compounds. As can be seen from electro-optical measurements (see Table 1) the tilt angle of SC-95 is higher. It means that the introduction of an additional $\mathrm{COO}$ fragment in the molecule improves the properties of FLC compounds and leads to the increasing of the tilt angle.

\section{Conclusion}

- A correlation between the chemical structures of new four-ring FLC compounds, the sign of the optical rotation and the tilt angle have been done.

- The prepared results allow to predict the structures of FLC compounds promising for the practical application and to choose the right direction for the synthesis of new FLC compounds with high tilt angle and a wide temperature range of the SmC* phase.

\section{Experimental}

The structures of the prepared compounds were confirmed by $1 \mathrm{H}-\mathrm{NMR}$ and mass spectroscopy. Phase transition temperatures were measured using a Linkam heating stage having a polarizing PZO microscope and also by using a Setaram DSC 92. Electro-optical studies were performed using cells supplied with ITO electrodes (with the resistivity about $30 \mathrm{Ohm} / \mathrm{cm}^{2}$ ). Aligning layers (nylon 6, polyimide (Al-1254) 100-120 nm) were spun at $3000 \mathrm{rpm}$ rate by a Spincoater and then baked at $180^{\circ} \mathrm{C}$ for 1 hour and unidirectional rubbed. The thickness of the cells was about $2 \mu \mathrm{m}$ measured in each case interferometrically. During electro-optic and X-ray measurements the temperature of the cells and of capillaries was controlled with the accuracy of $\pm 0.3^{\circ} \mathrm{C}$.

XRD measurements were made by using STOE Stadi 4 diffractometer with standard 1, 1.5, $2 \mathrm{~mm}$ capillaries (Hilgenberg).

\section{References}

1. I. Dierking, J. Phys. Condens. Matter 17, 4403-4410 (2005).

2. S. J. Watson, L. S. Matkin, L. J. Baylis, N. Bowring, H. F. Gleeson, M. Hird, and J. Goodby, Phys. Rev. E. 65, 03175 (2002).

3. V. Lapanik, V. Bezborodov, and W. Haase, New chiral compounds with high optical anisotropy and the FLC compositions on their base, Book of Abstracts, 20th International Liquid Crystal Conference, July 4-9, 2004, Ljubljana, Slovenia, SYN P-020.

4. V. Lapanik, V. Bezborodov, A. Minko, and W. Haase, Mol. Cryst. Liq. Cryst. 439, 1945 (2005). 